\title{
RESET
}

Recherches en sciences sociales sur Internet

$3 \mid 2014$

TIC, familles et célébrations

\section{An Entertainment Machine of filial piety}

A Look at Wii as a Gift for Parents

Un appareil de divertissement au service de la piété filiale. Lorsque la Wii est un cadeau destiné aux parents

\section{Holin Lin}

\section{OpenEdition}

Journals

Electronic version

URL: http://journals.openedition.org/reset/389

DOI: $10.4000 /$ reset.389

ISSN: 2264-6221

Publisher

Association Recherches en sciences sociales sur Internet

\section{Electronic reference}

Holin Lin, «An Entertainment Machine of filial piety », RESET [Online], 3 | 2014, Online since 31

December 2014, connection on 19 April 2019. URL : http://journals.openedition.org/reset/389 ; DOI :

10.4000/reset.389

This text was automatically generated on 19 April 2019.

(c) Association Recherches en sciences sociales sur Internet 


\title{
An Entertainment Machine of filial piety
}

\author{
A Look at Wii as a Gift for Parents \\ Un appareil de divertissement au service de la piété filiale. Lorsque la Wii est un \\ cadeau destiné aux parents
}

Holin Lin

The author would like to thank the two anonymous reviewers for their valuable comments and suggestions to improve the quality of the paper. I also want to thank the National Science Council of Taiwan for providing financial support for this research.

1 This article deals with a significant development in modern societies: how entertainment technologies, particularly computer games, find their ways into households and domestic life. The development I focus on involves the presentation of game consoles as gifts to elderly parents by their adult children. Such a process of gift-giving involves the values and beliefs of the larger society, and more importantly, is affected by the traits of the tech gifts. Here, the main research questions are: how is the unconventional gift-giving socially possible? What does it tell us about modern family life? Using data collected from Taiwan, I suggest that giving game consoles as gifts is a means through which young adults communicate values of filial piety, projecting imagined images of ideal family relations, and negotiating their intergenerational obligations in modern family life. It is suggested that the characteristics of technical artifacts also shape family relationships in the process of gift-giving.

\section{Introduction: game console and the changing family culture}

2 Computer games have long been connected with children and youth, and game machines or software are typically considered in many cultures as gifts that children receive from 
their parents. However, starting with the Nintendo Wii craze in 2007, a new media trend and public discourse are taking shape in which the Wii replaced the traditional image of video games as a "children's game machine" with a new image of a "machine for family entertainment". Although parents and children playing together was not seldom found in the pre-Wii era, since the launch of the Wii the public impression of game consoles has rapidly transformed from that of a toy for socially-isolated "nerds" to that of both a beneficial machine for family members' physical health and an entertaining media that builds social relationships and keeps families connected.

3 One indication of this change is the popular genre, "parents/grandparents playing Wii," among self-filmed videos on the Internet. Many of these videos filmed by young adults show grandparents or parents playing Wii alone or with family members across two or three generations in a joyful atmosphere. In the videos the young adults are in control of the technology products - the video camera or Wii - while the focus of the film is the elderly parents' pleasure, along with others' reactions and comments as they manipulate the digital technologies. The enormous number of viewings these home-made videos have enjoyed in recent years also shows the appeal of these unlikely gamers having fun in family contexts.

4 In Taiwan, a phenomenon that emerges along with the development of a more positive public image of gaming machine is "the game console as a gift to express filial piety" in which adult children buy a Wii for their parents to play with, to do exercise, and provide entertainment to avoid loneliness. In a way, the game console substitutes for adult children's absence in family life, and carries out the unfulfilled duty of taking care of elderly parents. This phenomenon not only provides a fertile ground to explore how entertainment technology is brought into family life; it also bears potential to shed some light on the social shaping of technology adoption. The spread of modern technology is often regarded as a natural result of its powerful and irresistible design. Yet the fact that the game is given as a gift demonstrates the social element in the spread of technology. At present, although the Wii craze is gradually fading, the phenomenon of leisure technology entering the family and home has become more frequent, marking a new family relationship intermediated through ICT (Information and communication technology).

5 Two reasons have often been cited to explain the trend of these unconventional gamers entering the gaming market. The first is about breakthroughs in the design of game machines, especially the development of an easy-to-use motion-sensing game controller and, more recently, the Balance Board (e.g., Sung, 2011). The other regards the change to creative and successful marketing strategies - a shift in development focus from video and audio effects of complicated games with high entry barriers to great family-friendly titles that target the light and casual gamers market (e.g., O'Gorman, 2008), thus expanding the gaming population beyond the game market predominantly full of young gamers. This study intends to extend the scope of analysis to consider the socio-cultural aspects of the process in which new information technology is assessed and obtained to adapt to new family forms and social needs.

6 To give one's elderly parents a game machine as a gift is by no means a simple matter. In addition to the negative image of videogames that would make it a socially inappropriate gift, the purchase of high-tech consumer goods often involve a set of knowledge more or less customized to the needs of consumers. Is this model the best choice for my parent(s)? What peripherals go with the machine? What game titles match the capability and need 
of my parent(s)? These questions must be answered before the actual purchase is carried out. Moreover, such unconventional gift-giving behaviors require a closer look at the actual context in which they are made possible. Where does the Wii-as-gift idea come from? How is the gift-giving sustained, negotiated and steered in specific family context? Are there common social or cultural denominators underlying these seemingly personal consumption decisions so that together they form a pattern? Last, but not least, what role do technical artifacts like the Wii play in mediating intergenerational family interaction? These are only some of the major issues that could be considered.

7 An important social background of this study is game companies' shifts in development focus and marketing strategies, combined with mass media coverage. Together they contributed to the new impression of "Wii as a social machine that enhances interpersonal relationships." The new representation of game play as healthy and sporty generates a Wii-friendly social atmosphere; together with the claim of filial piety fulfillment, this idea legitimates the Wii-as-gift-for-parent phenomenon. In daily inperson contact or on the Internet, young potential buyers can freely express their intentions to purchase a game machine, exchange experiences with each other, and even encourage others to buy one as a gift. The findings suggest that the new game machine is used in the adult children's struggle to reconcile the traditional cultural values of filial care with fast-changing family structures and contemporary life styles.

\section{Related Work}

Studies on digital leisure technology in the family context often focus on the young generation, concentrating on the relationship between digital games and family space, and the changes in social interactions and family relationships brought by digital games. Flynn (2001) introduced cultural exploration of the changing historical images of video game machines by analyzing the domestication process of wild machines on the streets brought into homes, and the transformation of the living room from an intimate leisure space mainly dominated by women to the center of family collective participation and interaction - a digital hearth. In the course of integrating game machines into family life, Flynn also observed, through ethnographic study (2003), the corresponding changes in family interaction and cultural norms, such as how to make the television meet the different needs of family members, the relationship between the location of video game machine installment and the stress on children's gaming activity as parents monitor them, and the corresponding changes in parenthood. Flynn discovered that the game space is a negotiated outcome of different family relationships.

Some studies emphasize the home as providing an important leisure space in childhood in their examination of the historical development of how children's game space shifted from outdoors to indoors as digital game machines entered the family (Zelizer, 1985; Livingstone, 2002). Studies on game space are also enriched by gender and digital divide perspectives that examine how the domestication of teenagers' leisure activities is intertwined with socio-cultural elements, and its influence on gendered leisure opportunity - such as young girls' game space or how game access becomes threatened or limited (Grundy \& Grundy, 1996; Jenkins, 1998; McNamee, 1998; Bryce \& Rutter, 2003; Bryce, Rutter \& Sullivan, 2006; Norris, 2004; Lin, 2008).

The influence of digital game machines on family interactions is another focus of related research. In the early 1980s, Mitchell observed how family interactions changed as the 
Atari game machine entered 20 families in San Francisco area. Her study (1984) discovered that most families used games as a family activity when they got together, but there were also differences in game participation according to gender and status. Fathers played more than mothers, boys played more than girls; however families consisting of all girls had the highest game participation level. Later studies also confirmed many conclusions from this pioneering study (e.g. Gailey, 1996).

11 Another stream of research on family leisure technology stresses the sociability afforded by digital game technology interfaces, studying the interactions supported by perceiving the television screen as an interaction interface and the home as a game space. The variety of digital game interactions shifted from the use of arcade games by various players and onlookers at playgrounds to playing game sets designed for only two players with reduced sociability as home use became more popular in the 1980s. However, there was increased sociability of digital games in the family when they became able to support four players simultaneously, and with the development of increasingly diverse game softwares during the 1990s (Williams, 2006; Phillips, Rolls, Rouse \& Griffiths, 1995).

Unlike the common view regarding the digital divide as a social problem that needs to be solved, Aarsand's research (2007) interestingly demonstrates evidence for a divergent view that the digital divide could provide meaningful resources in family contexts. For his ethnographic observation of family life, he videotaped the digital game play activities in eight Swedish families, and discovered different generations in a family invoked the notion of digital divide to interact with family members and fulfill their family relationship needs in different ways. Children and grandchildren appeared as the ones mastering the digital technology, thus controlling the game activities and strengthening their authority. Conversely, parents and grandparents positioned themselves as less knowledgeable, utilizing the divide as an interactional resource to access intergenerational dialogue and relationships that they previously struggled with.

13 Most of these studies place attention on what has changed within the family after the entry of new machine, and thus it is easy to discern the powerful impact of technology on family life. However, if we look further back into how the decision of acquiring a new technology product is being made, we just might find the decision to be a result of a more complex social negotiation. Furthermore, since the younger generation is the most likely user of new technologies, it is reasonable to position them as the major object of analysis. This research shifts its attention to the early stage of decision-making regarding family techno-product consumption, and emphasizes how intergenerational politics are incorporated into the whole picture.

14 Finally, the social legitimacy of technology use is an issue that has not been studied sufficiently. The use of television in parenting bears meaningful comparison with that of video game machines at home. Television and videogames have received similar attention for both are popular leisure machines with rich yet controversial content. Besides, console games also use a TV screen as a display platform that supports similar social interactions and mediation of family relations. Since the early time of television, it was popularly used as a surrogate for parenting, acting as the role of a babysitter (Maccoby, 1951; Zimmerman et al., 2007; Evans et al., 2011; Götz, 2007). Allowing children to watch television is often used as a convenient way to keep them occupied when the parent is busy (Rideout \& Hamel, 2006; Zimmerman, Christakis \& Meltzoff, 2007). However, such usage of the technology in parenting practice is not free of anxiety caused by social expectations of suitable parenting. Research shows that many mothers consider using the 
television as a babysitter because it allows them to do household chores, not because it can be used to replace interaction with their children (Gantz, 1982). Television's educational and other functions are also pointed out in addition to babysitting and entertainment (Zimmerman et al, 2007).

The research concern on proper parental mediation of children's television viewing showed that the adoption of family leisure technology needs social legitimacy. The ability to produce pleasure alone is not enough for a technology product to successfully enter the family; it also needs to be compatible with existing social norms of family roles. Responsible parents who monitor how their children watch television and filial children who give their parents videogame machines as gifts are both examples of socially acceptable use of technology. As a filial piety machine, Wii plays a babysitting role similar to that of television, only the ones who need care and company are now the elderly parents rather than the children.

16 Whyte (2004) and Jordan (1998) have both pointed out that the concept of filial piety is still deeply rooted in most Taiwanese people and practiced through different forms. Yet, gifting is a complex form of social interaction which involves both material exchange and value engagement. Gift-giving usually follows the reciprocity principle and accordingly generates moral obligation on the bearer's end to balance it. As Mauss perceptively points out, as the most fundamental form of society, gift-giving is a 'total social phenomenon' existing in all aspects of social life. It cannot be regarded as exchange between individuals, but between representatives of larger collectivities. (Mauss, 1990) A similar point is made by Bauman: "More importantly yet, gift-giving is not an episodic, not a selfcontained act" (1993:2). Empirical evidence in gift-giving also echos the importance of a larger social structure and cultural beliefs shared by the gift-givers and the recipients. For instance, in the past, electric home appliances that have a certain level of entry barriers, like the video recorder, have even been jokingly referred to by a Japanese television show as "unfilial" gifts for parents. Therefore the adult children may run the risk of being thought of as "insincere" for choosing the more complicated game machine as a gift, rather than safe choices of health supplements or care products ${ }^{1}$. The positive image of Wii and its user-friendly characteristics not only significantly lowers its access barrier, but also provides social legitimacy; together they bring the Wii-as-gift-to-parents phenomenon to realization. The adult children's explicit expectation of the gift -- playing Wii as a means to become more physically fit, to relieve boredom, or to have parent-child fun together, to show off in front of friends and relatives, along with implicit promises of playing with the parents or taking time to teach the parents how to play, contribute to a modern image of devoted children.

Media uses and gratification studies often regard media consumers as rational individuals who independently and actively select media products according to their own needs, to enhance their social and mental satisfaction. Rob Kling's well-known view of 'computerization as a social movement' offers a powerful alternative to technology adoption. Drawing upon the fast development of information technology in American history, he points out that computers are not just adopted as the result of individual utility-maximizing decisions, but instead are the outcome of social support mobilization promoted by various government offices, social institutions and IT industries (Kling, 1996; Iacono \& Kling, 1996).

18 Following this perspective, this study sees the Wii craze at home as a socially driven phenomenon. Media discourse and marketing strategies provide an appealing image of 
the new entertainment machine. The need to accompany the older parents offers a practical purpose for adult children who want to fulfill filial piety. Lastly, the young generation's close experience of digital gaming provides familiarity and background information to their gift-giving decisions. These changing conditions together turn the Wii, a game machine, into an ideal gift for older parents. Individuals are motivated by this collective imagination, and receiving recognition for their interaction from surrounding social groups further drives the motivation to decide whether to purchase a Wii, or a similar game. The users' experiences shared by consumers after purchase also serve as feedback to the surrounding social groups and reinforce the phenomenon.

\section{Data \& Methods}

19 How can the mutual shaping between technology artifact and social context be observed? Using several methods of data collection, this study looked at the actual experience of how entertainment technology products were selected, purchased and used in social contexts. This research adopted a critical discourse analysis approach, selected posted articles in Internet discussion boards on related issues as major materials for analysis, while conducting in-depth interviews with Wii-as-gift purchasers to follow what happened after the gift was presented. In addition to the overt descriptions of facts in posted articles and interviews, the analysis placed a special focus on the social construction of meaning behind the words, such as implicit intention and motivation, the content writers chose to present (or exclude), and the meaning they attached to these descriptions. Finally, mass media reports were also used as supplementary background to understand the role of Wii in the mainstream public discourse at the time.The detailed explanation of the data collection and research method are as below:

(1) Discourse analysis of posted articles on the Internet

21 This study chose the largest Internet discussion site in Taiwan - $\mathrm{PTT}^{2}$ - as the main source of data collection for two reasons. Socially, this is a popular gathering place of the technology product consumers community, and the scale and history of it attracted many users with basic digital literacy to develop discussion forums on different topics. Technically, since text-based computer-mediated discourse is free from competing influences of other communication channels or from physical contexts (Herring, 2001: 2), previous studies have shown that this type of computer-mediated communication can easily give people the feeling of having a direct communication, or even a sense of private exchanges with others (King, 1996). Such communication environments allow the participants to feel comfortable in expressing private family experiences. At the same time, people who have similar experiences or have something to say about the issue can respond, which allows the author to observe otherwise undetectable operations of social forces in the natural dialogue between the article writers and repliers, as well as how the community responded to this topic. Nevertheless, this is not to say that personal statements on such digital platform reflect what participants 'truly' think and feel. Selffiltering of what is to be said publicly and openly is almost certainly involved in such communication. Therefore, people could be more likely to post something as a filial child than otherwise. With this awareness, further in-depth interviews were conducted in the hopes of revealing more layers underneath the online public discourse, while the online personal statements still could be analyzed as reflections of a public common sense ${ }^{3}$. 

the most influential general discussion sites in Taiwan. Moreover, its archive contains all historical data since the discussion boards were created. For the purpose of this study, articles posted between November 2006 and January 2012 were collected, on PTT's "Wii" and "Nintendo" discussion boards, as the main source of data for analysis. At the Wii discussion board, keywords such as "family, father, mother, dad, mom" were used for searching related articles, and at the Nintendo board, the keyword "Wii" was used to filter related articles. The total number of discussion threads found related to this topic was 83. Each thread consisted of an original posted article and many other corresponding posts replying to it, and the total number of people who participated in posting or responding was $777^{4}$.

the parents but were unsure whether it was appropriate or which game titles should be bought along with it, and asking for recommendations from experienced consumers. Most of the posted articles' authors made a statement of their intention to buy the game machine, and some even described their family context for reference. The responding posts usually provided personal consumption experience. To a large extent, these discussion threads represent a community of new entertainment technology consumers and reflect larger social contexts behind the public imagination of these technology products.

To verify findings of the PTT discussion boards, more general searching on two other popular videogame online discussion forum sites in Taiwan-Bahamut and Gamebase, were conducted. In general, the contents were very similar to the ones on PTT. reports on the phenomenon collected from mainstream mass media. The reports served a couple of functions in this study: (a) to confirm the different social phenomena and multidimensions of influences that occurs as a Wii enters the family, serving as an integral background to such phenomena and marking the periodical changes of the Wii craze; (b) to serve as material for analyzing how mainstream social discourses create and enhance the image of "Wii as a family game machine" and inspire the public to purchase it.

This part of the data was mainly collected from a digital news database "United Daily News Group knowledge base," ${ }^{5}$ using the keyword "Wii" to search for articles between May 2006 and March 2012. After omitting articles that had nothing to do with the topic, a total of 864 article reports were found. ${ }^{6}$ This study also included some local media feature reports on the Wii. Generally speaking, the local media showed that the Wii craze began in 2007 and reached its peak in about the first half of 2009. When it became a big success 
in Taiwan's gaming market, a large quantity of media reports appeared describing the sharp increase in sales, the emergence of unconventional players (such as elderly people and housewives), or how family members played together enthusiastically. Starting from 2010, as other similar competing products (such as Kinect) entered the market, the heated trend in the media gradually faded. ${ }^{7}$

Drawing on the various data sources above, I analyze the discourse of the Wii in filial care for aging parents from three dimensions: the anticipated functions of the game machine, the image of technology for aging parents, and its implications on the empowerment of aging parents.

\section{Findings}

From the articles and responses collected from PTT discussion boards, the majority of people who bought or attempted to buy Wii for their parents were potential consumers who planned to buy the game machine or games but wanted some advice in advance. Only a few of them planned the purchase because they "received a hint from the parents" or were requested directly by them.

Some people admitted that it was their siblings or themselves who wanted to make the purchase but could not afford to buy it, so they hoped their parents would become interested and help contribute to the cost of the family game machine. Several of them gave the Wii to their parents as a gift on Father's or Mother's Day, their birthdays or during the New Year holiday, while still some gave them as a gift on normal days.

The majority of these discussions were under the title "If I want to buy Wii for my father/ mother as a gift" or "games suitable for parents/the family." Their motives for gifting were mainly for parents to do exercise, to avoid boredom or for the whole family to have fun together. They were most concerned about whether parent with low levels of technology literacy or no gaming experience would be able to accept Wii. Additionally, a few articles were about "how to regain the right of playing the game machine dominated by family members."

\section{Media-shaped image: a relationship machine and a healthy machine}

An important reason for the Wii craze certainly is related to the mass media coverage. The public discourse can be described as having three main themes. (1) Hot sales/out-ofsale discourse: typical descriptions such as "successful global sales," "crazy high demand," or "sold out everywhere" not only reflects the heated sales in the market but also roused the audience' curiosity and desire for it. ${ }^{8}$ This type of discourse has been used by the business sectors, civic groups and government sectors in reporting Wii-related events, ${ }^{9}$ also supported by stories on "celebrities playing the Wii." (2) Health/medical discourse: this type of discourse is included in reports on professional physicians' recognition of the medical effects of playing the Wii, ${ }^{10}$ anti-aging tips for the elderly, and the functions of keeping fit or losing weight. (3) Family game machine discourse: the focus of these reports is on a joyful environment where parents and children have fun together, in which the living room becomes a gym, or the Wii becomes a gift for the parents. This type of discourse also spreads out through many players' articles posted on personal blogs, discussion forums, or self-made videos uploaded on the Internet. 

myself, too." Many of the buyers' initial motive to buy the machine was because they liked it, but the sole reason of "self-entertainment and self-satisfaction" were insufficient for young adult children to overcome their guilt or anticipation of negative responses from others (for buying a game machine with hard-earned money). Some also worried that if they bought the game machine for themselves, their parents would scold them while they play at home. Therefore, while the young adult children may in fact be the main users of the game machine, they publicly claimed it to be a machine for fulfilling filial piety and generating family interaction. children's decisions and the legitimate reason of fulfilling filial piety provided the additional element needed to re-wrap the previously stigmatized video gaming into a fashionable gift of advanced technology for the family.

\section{Social pressure and the performance of filial piety}

The meaning of the Internet group discussion is not only about opinion exchanges or technical consultations over the technology product; these collective discourses also reflect the social expectation of "filial piety" in modern Taiwan society. Through the thoughtful descriptions, the adult children expressed their concerns for their parents and also their guilt and anxiety about being unable to practice filial piety well. In a posted article, a son described how he used Wii as a gift to repay his parents and assuage his guilt for asking his mother to buy a game machine in his childhood, when they were struggling economically. ${ }^{11}$

41 Even more commonly, young adult children who have just entered the work force express anxiety about not having time to care for or spend with their parents. A typical 
description of this category is "My family members are often working outside, so the Wii is for my parents to kill time (a gift on Father's Day this year XD)...I somehow think my mother doesn't feel so lonely when she is alone at home, after we bought Wii." ${ }^{12}$

Another noteworthy phenomenon is when gamers asked for opinions on which games are more suitable for parents, the other gamers responded to the two types of situations "play with the parents" and "have the machine replace them in accompanying the parents" - with clearly different attitudes. An author of a posted article, poemscout, wrote about how he wished to buy a Wii for his parents using money he earned from a part-time job so they could play by themselves or invite friends to play at home because he and his younger sister are both studying far from home. This article did not receive positive response like the ones asking for game suggestions, and even received several responses discouraging him to do so. The responses included "giving it as a gift in such circumstances often end up with the game machine piled in dusts (hardly used)," "It's a good intention to buy Wii for your father, but it's more important to make sure that he will like playing video games," and "the most important thing is that you play with them, or else the effect would be very limited."13

On the contrary, children who have succeeded in gaining their parents' interest in and entertainment from the games are highly supported and encouraged by others. The different responses to those children who only pay for the machine but do not intend to accompany their parents in playing demonstrates the importance of having a legitimate claim to be fulfilling filial piety. The expenditure of money alone is not enough to show filial love and duty.

Many articles posted by adult children acting annoyed or complaining about their parents occupying the Wii machine at home received responses that expressed the feeling of envy, such as "That's good to hear, the Wii at my home have become a decoration ${ }^{14}$," or "Congratulations! I envy you ... I wanted to be a filial son, but my parents are not interested in playing ${ }^{15}$." These discussions together reflect the high value of family relations and the fulfillment of social expectations conveyed by the purchase of this entertaining machine.

Both in the posted articles and interviews, the adult children all put effort in describing their thoughtful considerations of performing filial piety by buying a Wii for their parents. Ko, an author of a posted article (and one of my interviewees), said his mother was afraid to use technology products, and that not knowing how to use computerrelated products made her feel inferior to her peers at work and to other tech-savvy relatives, so he bought a Wii hoping to help his mother conquer technophobia. "She can now boot the machine, weigh her body weight, and then turn off the machine. I think this is already a big improvement (Ko, 31, Male)," he said.

Hui, another interviewee, mentioned that her father had Parkinson's disease and was encouraged by his doctor to stay physically active to prevent degenerative joint diseases. The doctor had also said that research results indicated playing the Wii can help patients with their balancing ability, so she bought the machine hoping to encourage him to be more active and help deal with the psychological effects during the advanced stage of illness. She said her father had indeed gained self-dignity in achieving the highest scores in every game, and also prevented many family confrontations by promoting a more positive atmosphere at home. "I think that (playing the Wii) was his only interest and sole source of happiness during his 11 years of illness (Hui, 30, Female)," she said. 
Promoting family interaction and having fun together is emphasized when buying the game machine. In a posted article, markbex told how he used the Wii to show photos taken during family outings and to share with the family. ${ }^{16} \mathrm{~A}$ typical article ${ }^{17}$ described how the author taught his parents to boot the machine, understand the Japanese interface, ${ }^{18}$ choose games, and accompanied them in playing.

Seeing that my mom always sits there watching TV until she falls asleep, and my dad is unable to do daily exercise because of his unstable working hours, I've decided to buy a Wii. My younger brother is going to military service, so dad and mom needs to be taken care of... Wii Sport is a must-buy, especially for training the body. I spend more than a hour playing with my parents, to the extent that their bodies feel sore for a few days. (oh yeah, I got them caught on the hook!)... Now my dad can serve an ace (in tennis), and also shouts "Yeah" like when I score... The elderly family members need to be taught the control movements one at a time and how to catch the right timing, and also to be accompanied for several days. They will become interested in the games... Hope everyone can have fun with your parents!!!

Many responding articles conveyed a general emotion of envy for the family pleasure expressed in such articles. The social imagination of the family game machine joins the need for modern approaches and successfully transformed the personal game machine into a filial piety machine.

\section{The gamer generation yearning to be understood}

In both posted articles and during interviews, these consumers who purchased a Wii for their parents have shown great enthusiasm in describing how their parents enjoy the games or even become obsessed with playing. Expressing a tone of fondness and excitement, they spoke about how "my parents play crazier than I do" or how their parents actively challenged them to play and "we children can't even beat them." These descriptions have become a common theme in this type of article.

My dad has become obsessed with the bowling game in Wii Sports. Starting from the basic game of achieving a perfect score of 300 points, now he is playing the challenge to clear 20 lanes. His latest goal is to clear 20 lanes for all the Mii avatars, so what I hear from him when I get home every day is his report on which Mii avatar has achieved clearing 20 lanes or which one got more than 200 points. ${ }^{19}$

These descriptions echo the point Jane McGonigal makes that the stronger social connectivity of video games can bring two types of emotions to friends and family: happy embarrassment and vicarious pride ${ }^{20}$ (2011: 83-89). Yet a third emotion exists in addition to those McGonigal cites. While adult children enjoy seeing parents that previously didn't play games now even beat them in the games, they also express a strong feeling of "now you finally understand why I used to like playing games, huh?"

51 When proudly showing off their success in fulfilling filial piety by making their "parents become obsessed with/addicted to playing videogames," these adult children often similtaneously show a strong emotion of relief because their game playing behaviors are finally justified and understood: "the parents finally understand that playing video games isn't so bad, and children who play games aren't bad."

When parents and children shift their positions in playing, the adult children feel a sense of mutual understanding and reconciliation between the two generations. An interviewee (Nintendo, 29, Male) who has been a gamer since childhood and has tried finding 
appropriate games for his parents to become interested in Wii, said "I always wanted my parents to understand the fun of playing video games...":

From the time it was purchased, my parents' game playing time has steadily increased. Now I can only sneak up to play for a little while when they are sleeping at night Q_Q... Now (it seems like) there are no adults in my home. When they are crazy about the games, they act more like a child then I am $(==)$. But it's a good result, at least I'd never thought that I can play video games with my parent.

Parents that became fond of playing games often break their own stereotypes about game playing being "a hobby that makes their children addicted and lose their will to make progress in life," and even reconsider their parenting style. After Hui had successfully helped her father come to enjoy playing games, her mother apologized to her for not allowing her and her siblings to play videogames so frequently when they were younger. Hui's mother also used it as an example to persuade her father: "See how much fun you're having now? How can you stop them from doing what they feel happy about?"

This yearning for parents who previously despised playing games (and the kids who played them) to do justice to computer gaming and to their childhood memories, is echoed by others:

\begin{abstract}
Having read everyone's articles, such as the ones that are about how family relationship improved after playing the Wii together... It still didn't work out in my home, because my parents hold a fixed attitude toward playing games. "No matter how the playing methods change, video games are always video games - something that time is wasted on" is what they hold in mind. So now only my sister and I play it... my parents still scold at us when they pass by... When I began to believe everyone has their own likes... and its okay that I couldn't make my parents like it, I suddenly remembered that a previous article on this discussion board had mentioned the Wii can be used as a photo viewer. So I used it to show photographs taken in family outings in the theater view mode with music, and the feeling was great. XD The whole family was attracted by it, and my parents began to accept this machine. $\mathrm{XD}^{21}$
\end{abstract}

For a generation brought up under the influence of digital gaming culture, the acceptance of game playing from their parents symbolizes that their parents finally understood them. So the family recreation and communication through the entertainment technology also have the meaning of bridging the generation gap.

\title{
The machine that brings generations closer and the game titles that separate them
}

However, the effect of generation convergence from the addition of family game machine is not complete, as a vague generation gap still remains. The game machine can be enjoyed across generations, but the choice of game titles still needs to be differentiated according to different generations. Many of the discussion points were on "what kinds of games are appropriate for elderly people."

As these discussions invite "the unconventional gamers - the parents" to the game world, they also reflect the common consensus that suitable games for the parents are sports and small games, such as Wii Sports, Wii Fit, Fishing Master, Cooking Mama, Wii Sports Resort, Kororinpa Marble Mania. Other games such as Super Smash Bros, Mario Kart, Rayman Raving Rabbids, the Legend of Zelda series or other RPG games are only suitable for the younger generations. In other words, easy-to-handle games are appropriate for parents, while complex games are only suitable for children. 
discussions emphasize the line that remains between the generations that have been drawn closer to each other through game playing. From the adult children's description, these parents that cannot cross the line of game separation are normal, and they need to be instructed or directed like children. The adult children use affectionate but condescending tones to tease their parents' for their clumsiness when playing games, and their unfamiliarity with technology. ${ }^{22}$ The few parents that crossed over the line to play complicated games considered only for young people, and even do better than their children, sometimes cause anxiety for the children. ${ }^{23}$

\section{Further Analysis \& Implications}

Interestingly, the backgrounds of the people who posted this type of purchase (plan) articles are very alike: the intention to purchase the games arose after they graduated from college and worked for two to three years, but their limited salaries meant that the cost of a Wii takes up a large proportion of their monthly salaries. Most of them were unmarried and living with their parents, or married for a couple of years with their own residence. Also, many of them didn't have many siblings to accompany their parents when they purchased a Wii.

The parents were mostly in their early fifties, and were nearly or already retired, so they had more empty-nest time because their children had grown up, and their feelings of boredom or emptiness had become a common concern for their children. The physical conditions of the aging parents at this stage also needed to be strengthened but most could do without medical care.

61 These profiles of people who shaped the buying-Wii-for-parent phenomenon represent a more general social trend in Taiwan society. Economically, the young adult children's salaries are mostly incompatible with the parents who have built a secure financial base, and cannot afford to provide financial support or daily necessities for their parents. Sometimes, the parents still have to provide financial support or room in the home for the children to ease their burden from cost of living.

In the urban nuclear family structure, the children's responsibility to practice filial piety falls on satisfying their parents' emotional needs through "accompanying" or "pleasing" them. An obstacle in practicing filial piety in a nuclear family is that often the geographical space between the members is expanded, and the young adult children often find it hard to fulfill filial piety while they are busy working. The game machine serves as an "imaginary companion" and also shows the feeling of guilt from these children who cannot accompany their parents.

An interviewee, Simoha, said she bought the Wii because her parents have no particular recreational hobbies, but as the parents are aging and have more spare time, the children are getting busier with their lives and have not much time to spend with their parents. To assuage her guilt, Simoha provided a substitute by giving her parents the Wii as a gift. So in the name of filial piety, the modern nuclear families have now found a new form of performing, fulfilling or even showing off filial piety through the technology product that children of the gaming generation are most familiar with.

64

From the viewpoint of power relations mediated through technology products, through the behaviors of instructing the parents with insufficient gaming literacy to boot the game machine and choose games, and accompanying them in playing, the adult children 
have somewhat reversed the family recreational form of "the children following the parents' instructions" from their childhood.

However, as the family game machine has brought the different generations closer, it has not altogether reversed the power relations entailed in technology use between the different generations. The selection of the game machine and the predominance in gaming techniques are still in the hands of the adult children's generation, and the choice of games have also become an important symbol of marking out the different generations. Even so, the parents that have become familiar with digital games have also created an image of techno-savvy in the eyes of their peers, friends and relatives, enhancing their status and power.

\section{Summary}

In summary, Wii-as-gift for-parent became a noticeable phenomenon because of the interwoven effects of certain structural factors. As the starting point of the developing process, mainstream media powered by game companies' market strategy replaced the conventional image of game console as addictive toys for youngsters with an image of healthy, family-bonding relational machines. This new public image then paved the way for the making of new family entertainment machines. For a generation of young adults who identified with traditional values of filial piety yet had less means to carry out their obligations, a game machine appeared to be a trendy and affordable gift to do double duty by keeping their parents occupied while the adult children were not home to enjoy the fun of it together.

For the generation of young adult who grew up with video games, game machines and their encompassing knowledge also serve as an important medium to connect to both their peers and their culturally distanced parents. With a socially praised course of filial piety, the potential buyers' questions regarding purchase and usage of game consoles received enthusiastic responses in online forums. Some portraits of the game machine that improved family relations and dissolved generation gaps gained special admiration on forums. The formerly doubtful leisure technology now contributes to a better family life with an undeniably significant role mediating the process. Gaming is one of the most prevailing aspects of the culture of the younger generation, and the fact that the parental generation 'fell for it' has symbolic meanings beyond the fact itself. To many adult children, their parents' acceptance of game machines was also a recognition of their formerly disapproved lifestyle in their growing-up years. On the parent's side, their general lack of digital literacy required in playing computer games drove adult children closer in helping out and in playing together. Everything considered, in such an unconventional gift-giving process, traditional values found a way to be incorporated into modern family life in Taiwan society. 


\section{BIBLIOGRAPHY}

AARSAND Pal André (2007). "Computer and Video Games in Family Life The digital divide as a resource in intergenerational interactions", Childhood, 14(2), pp. 235-256.

BAUMAN Zygmunt (1993). Postmodern Ethics, Cambridge, MA, Basil Blackwell.

BRYCE Jo \& RUTTER Jason (2003). "The gendering of computer gaming: Experience and space", in Fleming Scott and Jones Ian (eds.), Lesire cultures. Investigations in Sport, Media and Technology, Eastbourne, LSA Publications, pp. 3-22.

BRYCE Jo, RUTTER Jason \& SUlLIVAN Cath. (2006). “Digital games and gender” in Rutter Jason \& Bryce Jo (ed.), Understanding Digital Games, London, Sage, pp. 185-204.

CHANG Jui-Chu (2010). Gift-receivers' Behavioral Reactions in the Grey Market, Master thesis, National Chung Hsing University, Taichung.

EVANS Cortney A., JORDAN Amy B. \& HORNER Jennifer (2011). "Only two hours? A qualitative study of the challenges parents perceive in restricting child television time", Journal of Family Issues, 32 (9), pp. 1223-1244.

FLYNN Bernadette (2003). "Geography of the digital hearth", Information Communication \& Society, 6 (4), pp. 551-576.

FLYNN Bernadette (2001). "Video Games and the New Look Domesticity", Bad Subjects, 57 (October), Available at: http://eserver.org/bs/57/flynn.html.

FLYNN Bernadette (2003). "Geography of the Digital Hearth”, Information, Communication and Society, 6(4, December), pp. 551-576.

GAILEY Christine W. (1996). "Mediated messages: Gender, class, and cosmos in home video games", in Greenfield Patricia M. \&. Cocking Rodney R (eds.), Interacting with video, Norwood, Greenwood, pp. 9-23.

GANTZ Walter (1982). "Television the Surrogate Parent: Uses and Correlates of Television as Babysitter", Annual Meeting of the Association for Education in Journalism, 65.

GÖTZ Maya (2007). “Television Viewing from Before Birth up to the Age of 5: A Review of Research Literature", Televizion, 20, pp. 12-17.

GRUNDY Anna Frances \& GRUNDY John (1996). Women and computers, Bristol, Intellect Books.

HERRING Susan C. (2001). "Computer-mediated discourse", in Schiffrin Deborah, Tannen Deborah \& Hamilton Heidi (eds.), The Handbook of Discourse Analysis, Oxford, Blackwell Publishers, pp. 612-634.

MCGONIGAL Jane (2011). Reality Is Broken: Why Games Make Us Better and How They Can Change the World, London, Penguin Books.

JENKINS Henry (1998). "Complete freedom of movement: Video games as gendered play spaces", in Cassell Justine and Jenkins Henry (eds.) From barbie to mortal kombat: Gender and computer games, Cambridge, MIT Press, pp. 262-97. 
JORDAN David K. (1998). "Filial Piety in Taiwanese Popular Thought", in Slote Walter H. \& de Vos George A. (eds.) Confucianism and the Family, Albany, SUNY Press, pp. 267-284.

KING Storm (1996). "Researching Internet communities: Proposed ethical guidelines for the reporting of results", The Information Society, 12(2), pp. 119-27.

KLING Rob (1996). "Hopes and Horrors: Technological Utopianism and Anti-Utopianism in Narratives of Computerization", in Kling Rob (eds.), Computerization and Controversy, San Diego, CA, Academic Press, pp.41-58.

IACONO S. \& KLING R. (1996). "Computerization Movements and Tales of Technological Utopianism" in Kling Rob (ed.), Computerization and Controversy, San Diego, CA, Academic Press, pp. 85-105.

LIN Holin (2008). "Body, space and gendered gaming experiences: a cultural geography of homes, cybercafes and dormitories", in Kafai Yasmin B., Heeter Carrie \& Sun Jennifer Y. (eds.) Beyond barbie and mortal kombat: new perspectives on gender and gaming, Cambridge, MA, MIT Press, pp. 54-67.

LIVINGSTONE Sonia (2002). Young people and new media: Childhood and the changing media environment, Thousand Oaks, Sage.

мAссову Eleanor E. (1951). "Television: Its Impact on School Children", The Public Opinion Quarterly, 15(3), pp. 421-444.

MAUSS Marcel (1990). The Gift: The Form and Reason for Exchange in Archaic Societies, New York, WW Norton.

MCNAMEE Sara (1998). "Youth, gender and video games: power and control in the home", in Skelton Tracey \& Valentine Gill (eds.), Cool Places: Geographies of Youth Culture, London, Routledge, pp. 195-206.

MITCHELl Edna (1984). "Home video games: children and parents learn to play and play to learn", Resources in Education, 19(10), p. 89.

o'GoRman Patricio (2008). "Wii: Creating a Blue Ocean the Nintendo Way", Parlemo Business Review, 2, pp.97-108.

PHILlips Carol A., ROLLs Susan, RouSE Andrew. \& GRIFFITHS Mark D. (1995). "Home video game playing in schoolchildren: A study of incidence and patterns of play", Journal of Adolescence, 18, pp. 681-697.

RIDEOUT Victoria \& HAMEL Elizabeth (2006). The media family: Electronic media in the lives of infants, toddlers, preschoolers and their parents, Henry J. Kaiser Family Foundation.

SUNG Kelvin (2011). “Recent Videogame Console Technologies”, Computer, 44(2), pp.91-93.

WHYTE Martin K. (2004). "Filial Obligations in Chinese Families: Paradoxes of Modernization", in Ikels Charlotte (ed.) Filial piety: Practice and discourse in contemporary East Asia, Stanford University Press.

Williams Dmitri (2006). "A Brief Social History of Game Play" in Vorderer Peter \& Bryant Jennings (eds.) Playing Video Games: Motives, Responses, And Consequences, London, Routledge, pp. 229-247.

ZELIZER Viviana A. (1985). Pricing the priceless child: The changing social value of children, Princeton, Princeton University Press. 
ZIMMERMAN Frederick J., CHRISTAKIS Dimitri A., \& MELTZoff Andrew N. (2007). “Television and DVD/video viewing in children younger than 2 years", Archives of Pediatrics \& Adolescent Medicine, 161(5), pp. 473-479.

\section{NOTES}

1. A survey in Taiwan showed that giving food and personal care products to elderly people as presents is less likely to cause dissatisfaction (Chang, 2010). In a Taiwanese TV commercial, a married daughter visits her father's house, and loudly claimed, "Hey, Dad, once again, I'm bringing Centrum Silver to see you!" Centrum Silver is a popular product of multivitamins in Taiwan, featuring adults over 50 by Pfizer.

2. PTT is a Bulletin Board System (BBS). In the early 1990's, Taiwan's Ministry of Education linked the Taiwan Academic Network (TANET) to the Internet. Afterwards, many text-only Bulletin Board System (BBS) that were easy to establish began to be set up at university campuses. Among them, the PTT set up by students of National Taiwan University in 1995 gradually developed into the largest independent online discussion site. Currently, the peak of simultaneous online users have reached about 150,000 every day, with an average of 20,000 new posted articles every day, and the highest accumulated account-times in one day have even reached more than 4 million.

3. I would like to thank the anonymous reviewer who brought this issue to my attention and the helpful comments provided.

4. Repeated articles have been excluded.

5. The United Daily News Group knowledge base enlists the contents of several local newspapers. Although it does not cover all the major print media in Taiwan, it is the most complete and largest online news database at present.

6. Systematic searches resulted in 3,096 reports, but many of them that were about stock prices, industry news, latest products, or the Wii as a gift for lucky draws at various events, were excluded from the reference data.

7. However, the fading trend of Wii-related reports in the media does not necessary mean the family game machine, represented by the Wii, have withdrawn from the market, or that unconventional players have quitted, but rather showed that the game machine may have become too popular and no longer an exceptional event noteworthy of reporting.

8. For example, "The Wii storm aroused around the world," published on Business Next on $2007 / 2 / 25$.

9. This type of reports included accommodating certain hotel or motels that provided the Wii machine to play for free, Wii-playing contests at graduation ceremonies, teacher appreciation banquets, community events, summer camps, government or private business sectors using the Wii as a gift for lucky draws, and even funeral services providing paper-made Wii for burning to the deceased.

10. Psychiatrists' claims about the medical effects of playing the Wii for people who suffers from depression, the rehabilitation functions for patients that got a stroke, the prevention of worsening dementia for elderly people, and other general healthy descriptions.

11. Purple Ink, "An unforgettable story - about SEGA and Wii," 2007/12/14, in the China Times.

12. "[Question] games suitable for parents," posted by Anop on 2007/8/11, at PTT Wii discussion board.

13. Author's posted article "[Question] Want to give a Father's Day gift...," posted by Poemscout, on 2011/7/17, at PTT Wii discussion board.

14. Author Ducksky's reply to an article posted by W11, titled "My mother woke me up early in the morning to play Wii Fit," replied on 2008/3/2, at PTT Wii discussion board. 
15. Author tezuka1115's reply to an article posted by hsnulight, titled "If I want to buy Wii for my parents," replied on 2011/3/17, at PTT Wii discussion board.

16. "Photographs taken during New Year's holiday can be shared with family members by using Wii," posted by Markbex on 2010/2/14, at PTT Wii discussion board.

17. "Playing Wii with dad and mom," posted by mmonkeyboyy on $2007 / 1 / 14$, at PTT Nintendo discussion board.

18. Agency problems between Nintendo and its long-term exclusive agent in Taiwan - Hakuyu, had caused the timing for Wii's launch in Taiwan postponed for about two years. As the official launch was postponed to 2008 and agency disagreements between the companies further led to Hakuyu filing a lawsuit against Nintendo in 2011 for terminating their long-term exclusive agency, many gamers in Taiwan had bought parallel imported Wii machines from Japan between 2006 and 2008. Therefore the entry barrier of playing Wii with Japanese interface was even higher for people who did not understand Japanese.

19. "My dad is frantically addicted to sports", posted by dayanmeme on $2007 / 4 / 15$, at PTT Nintendo discussion board.

20. "Happy embarrassment" refers to a rewarding feeling we experience when we play a good game and soundly beat, or are beaten, by people we really like. We crave the experience of teasing each other about it (2011:83). "Vicarious pride" refers to a satisfying feeling from playing over someone else's shoulder, and giving advice and encouragement (p.87).

21. "What my parents really enjoyed...," posted by nachimu on 2007/2/9, at PTT Nintendo discussion board.

22. For example, "My mother didn't even know how to play a CD, but now she has secretly played to breaking records" or similar descriptions were often seen. (Author RXCPU's reply to a posted article "[Ask] If I want to buy Wii for my parents" on 2011/3/17, at PTT Wii discussion board.)

23. For example, a person posted an article about his mother who was usually uninterested in the Wii Fit that he had bought, but handed him some money and asked him to buy a dancing game that was considered rather difficult for him because he has hard time coordinating his limbs to keep up with the game, so he did not share his mother's enthusiasm. (Author Kenny1206's posted article "Let's talk about our experiences of bringing Wii home!" posted on 2008/2/11, at PTTWiidiscussion board.)

\section{ABSTRACTS}

Starting with the Nintendo Wii craze in 2007, a new media trend and public discourse are taking shape in which the Wii replaced the traditional image of "parents-to-children game machine" with a new image of "machine for filial piety". Grown-ups bought Wii as a gift for their parents to fill in their own absence in the family life, or to carry out unfulfilled duty in taking care of elderly parents. In this study, the meaning of such phenomenon is analyzed as more than just a successful market development strategy to incorporate unlikely gamers. The new game machine is used in the adult children's struggle to reconcile the traditional cultural values of filial care with fast-changing family structure and contemporary life style.

Dans la foulée de l'engouement pour la Nintendo Wii en 2007, l'idée selon laquelle la console de jeux est traditionnellement un "appareil offert par les parents pour les enfants" se voit supplantée dans les médias et le débat public par celle, nouvelle, d'un "appareil de support de 
piété filiale". Des adultes se mirent à offrir des Wii à leurs parents de façon à combler leur propre absence dans la vie familiale, ou pour remplir leur devoir - inaccompli - de prendre soin de parents âgés. Dans cette étude, le phénomène n'est pas simplement envisagé comme la réussite d'une stratégie de marketing consistant à toucher un public de joueurs jusque là considéré improbable. La nouvelle console de jeux est mobilisée par des enfants adultes dans l'objectif d'articuler les valeurs traditionnelles de l'attention filiale avec les transformations rapides de la structure familiale et les styles de vie contemporains.

INDEX

Keywords: Nintendo Wii, gift, filial piety, home entertainment machine, family relationship Mots-clés: Nintendo Wii, cadeau, piété filiale, appareils de divertissement à domicile, relations familiales

\section{AUTHOR}

\section{HOLIN LIN}

National Taiwan University, Department of Sociology 